\title{
El sello ignaciano
}

\section{Fernando Azuela, Centro de Reflexión Teológica, San Salvador, El Salvador.}

Gran difusión ha tenido en las publicaciones de la Companía de Jesús la fotografía del sello con que, durante mucho tiempo, lacraba su documentación el superior general. Mango de madera, placa de metal, el $I H S$ en el centro y, alrededor, Sigillum Praepositi (sello del preposito general). Un sello material que -asi, en lacre - ha dejado de emplearse... Pero ¿cuál es el sello espiritual con que el primer preposito y fundador, Ignacio de Loyola, marcó a la Companfía?, ¿cuáles son las caracteristicas que, por ser esenciales, él concibió cono indelebles, irrenunciables, imprescindibles?

Durante un tiempo, Ignacio consideró la posibilidad de ingresar en una orden antigua muy necesitada de reforma. Después, de tal manera se apasiona, junto con los compafteros de París, por la fundación de un nuevo instituto que recurre a todo lo imaginable, antes que verse derrotado por la oposición de varios cardenales significativos. ¿Qué aportación inédita sentí, pues, Ignacio que ellos podian ofrecen en ese siglo XVI, el mayor enjuiciador de la Iglesia, el siglo de la reforma protestante?

Preguntar así, sobre la aportación específica de la Compantía de Jesús al mundo y sobre sus características esenciales, equivale a preguntar por su carisma. Carisma... esa gracia particular, esa inspiración que es concedida a una o varias personas para que la compartan con los más posibles: una visión especial del ser y del quehacer.

Ahora bien, el cardenal Guidiccioni y los demás opuestos al nacimiento de una orden nueva, quizá se alarmaron por lo más externo y circunstancial de las innovaciones de Ignacio. Nosolros, al preguntamos por el carisma, necesitamos ir al fondo, a lo trascendental. Incluso es posible que los énfasis más jesuíticos no sean "la exclusiva" de los jesuitas. No importa: precisamente los carismas son dados para ser compartidos. Lo importante es que ahi esté plasmada la impronta del fundador. 
Y ¿entonces? Así consideradas las cosas, siete son quizá las características más destacadas que el sello ignaciano dejó para sus seguidores, todas intimamente conectadas, pero suficientemente distinguibles. A los jesuitas, el recorrer estas características -ahora que estamos conmemorando los 450 anjos del nacimiento de la Compafía (1540) y los 500 afios del nacimiento de Ignacio (1491) - nos propicia una saludable oportunidad de examen: ıqué tan fieles estamos siendo al carisma original, a la herencia de ese padre y maestro Ignacio?

\section{1. "Mayormente" aferrados a Dios-siempre-mayor}

Ignacio de Loyola fue arrebatado de manera subyugante por un Dios percibido como el Unico, el Absoluto, origen y fin de wodo... Es lógico que, al formular los principios que han de regir a la Compafía subraye esta ordenación prioritaria a sólo Dios: "...para servir a sola su divina Majestad..."1.

Hombre de férreos principios, Ignacio visualiza a los jesuitas precisamente como hombres de "Principio y Fundamento", en congruencia con la prioridad espiritual que él vive desde su conversión, y comparte en el frontispicio de sus Ejercicios: "El hombre es criado para alabar, hacer reverencia y servir a Dios nuestro Seflor..." ${ }^{n}$. Dios ante todo, Dios mayor que todo.

La intuición del converso de Pamplona sobre este primado absoluto de Dios se fue consolidando en una genuina escuela de relotivizacion. Diecinueve aflos, descle su conversión hasta la fundación de la Compania, fue llevado de la mano por un Dios que se le revelaba como siempre mayor, un Dios permanente sorpresa, por quien habia que ir renunciando a todo lo demás, aunque, de momento, pareciera indicado. E Ignacio fue renunciando a la idea de ocultarse en un monasterio, al desalifo personal e inclementes ayunos, al proyecto de imitar a Jesús - como una copia al carbón- en Tierra Santa, a su condición de peregrino solitario, a dosis de oración e Indices de pobreza que le impedian esudiar, y etc., etc... Todo es relativo, fuera de Dios, el único Absoluto; a todo hay que ser "indiferentes", excepto a Dios siempre inasible, inalcanzable, sorprendente, siempre mayor..., en quien reside toda esperanza: "...es menester en El solo poner la esperanza... ${ }^{\text {n4 }}$.

Pero falta la contraparte. Esa experiencia fascinante y sobrecogedora del Dios mayor lleva a Ignacio - el apasionado hasta extremos de locura- a descalificar loda respuesta tibia o mediocre de nuestra parte. Un Dios mayor sólo es compaginable con una correspondencia "mayor". Y queda acuflado el lema de la Compania Ad Maiorem Dei Gloriam. Los jesuitas, hombres de "Principio y Fundamento", son impensables si no operativizan esto en una entrega eximia: sujetos que eligen "lo que más conduce"s, que buscan con atinada puntería ese bien que "cuanto más universal es más divino"b. 
Por eso, la cuarta parte de las Constituciones, consagrada a los "medios de ayudar a los prójimos", sobreabunda en este enfoque: deberán atenderse las personas y lugares que, siendo aprovechados son causa de que se extienda más el bien; o los sitios donde mayor es la cizafla y hay que cargar más la mano; y deberán emprenderse las obras más urgentes, más seguras, de más fácil conclusión y las más duraderas... Ante un Dios-siempre-más, los jesuitas deberán ser los hombres del "más".

\section{Seguidores de Jesús - rey eterna— pobre y humillado}

Un Dios mayor, incesante novedad, siempre irreductible a nuestras categorfas, cautivó a Ignacio de Loyola: el Absoluto a quien debemos adherimos relativizando todo los demás: "salud...enfermedad, riqueza...pobreza, honor...deshonor, vida larga... vida corta..."

Pero esta experiencia de Dios no tiene nada que ver con un ser lejano. ; Todo lo contrario! El Señor que irrumpe en la sala del castillo de Loyola, donde Ifigo convalece de la piema herida, es palpablemente cercano. Tanto que Ifigo casi podra decimos con San Juan: "lo que hemos oído, lo que hemos visto con nuestros ojos... y tocaron nuestras manos, esto les anunciamos..." Cristo que lee (a falta de novelas de caballeria), los extractos que va escribiendo con tinta roja y, sin duda, las contemplaciones en el desaciento expiritual de Manresa, conlleva tal encarnación de Jesús —un rostro tan cercano- que mil veces quedan superados los estremecimientos que Inigo habfa sentido ante los grandes Fernando el Católico y el emperador Carlos V de Espanta.

Este encuentro persona a persona con Jesús -rey eternal que desplaza a todo rey temporal- es el generador de un hombre nuevo en Inigo y en todo auténtico jesuita. El encuentro persona a persona abre un diálogo entrafiable de corazón a corazón que no callará jamás... Por amor apasionado, el fundador de la Compantía y sus seguidores se enrolan en la causa del reino con un alistamiento de tono militar presente en los documentos constitutivos de la nueva orden: elegida por quien desea ser "soldado de Cristo", por quien decide seguirlo para "conquistar todo el mundo"10 y tenido por perverso caballero"11.

Con todo, el seguimiento de Jesús que debe estar en la génesis de toda vocación jesuita, es una opción diametralmente opuesta a victorias renombradas, a botín de riquezas, a títulos nobiliarios...; a cuanto ambicionó Intigo antes de que un nuevo y definitivo rey se cruzara en su camino... Porque el Jesús que le apasiona ardorosamente es el del evangelio, sin componenda alguna, por quien podremos "militar" siempre y cuando estemos dispuestos a hacerlo "debajo del estandarte de la cruz"12, "aborreciendo en lodo y no en parte cuanto el mundo ama y abraza... y deseando con wodas fuerzas posibles cuanto Cristo nuestro Seffor ha amado y abrazado"13, "...deseando pasar injurias, falsos testimonios, 
affentas y ser tenidos y estimados por locos... por desear parecer e imitar en alguna manera a nuestro Creador y Seflor Jesucristo, vistiéndose de su vestidura y librea..."14.

Tal es la propuesta de Ignacio, el del vestido raldo -el "hombre del saco"-. quien ha mendigado diecinueve afios de puerta en puerta, el encarcelado de Alcalá, el encadenado de Salamanca, el procesado repetidas veces por la Inquisición (aunque nunca condenado). Ideales de vida, no teóricos, sino ampliamente experimentados, que él, como primer general de la Companía, va plasmando en las Constituciones, desde el interior de la curia generalicia, una casa destartalada, junto a Santa María degli Astalli, en Roma.

El comer, beber, vestir y dormir de los jesuitas deberá ser como cosa propia de pobres. Todo servicio sera hecho "graciosamente, sin esperar ninguna humana paga ni salario por su trabajo"15, ni habrá cepos para colecta de limosna en los templos a cargo de la Compantía. Considera Ignacio tan vital el seguimiento de ese Jesús que vivió a la intemperie -en descampado- que los jesuitas se comprometerán con un voto a no alterar nada de lo estatuido sobre la pobreza, si no es para estrecharla más; y a obedecer con cuidado especial en lo tocante a la enseftanza de los niffos y de los hombres rudos. Obviamente, sabe Ignacio que el contacto con los empobrecidos garantiza la cercania con Jesús. Es su experiencia y la desea para todos: tanto los novicios como los teólogos enviados al concilio de Trento tienen una consigna: enseftar la doctrina a los niffos y servir a los pobres en los hospitales.

Asi entendemos el rechazo aguerrido de Ignacio ante el peligro inminente de que los jesuitas sean consagrados obispos. "Sería perder nuestro espíritu —oda simplicidad y bajeza - sería la ruina de la Compantia", escribe a Fernando, rey de Austria ${ }^{16}$. Los jóvenes desprendidos se desilusionarlan de la orden; los ambiciosos, por esto buscarian abrazarla. Asi entendemos el voto de los jesuitas de no aspirar a dignidades, y entendemos un sistema de gobiemo que intenta rancelar todo juego de politiquerías humanas.

Las persecuciones injustas, en cambio, regocijaban a Ignacio. "Con un rostro muy sereno y alegre" cuenta Rivadeneira (biógrafo, testigo ocular) que recibió el aviso de la "contradicción que hacía a la Companía un príncipe tan grande como era el arzobispo de Toledo"17. Los jesuitas estaba siguiendo de cerca las huellas de Jesús pobre y humillado...

\section{Apóstoles por esencia}

Jesús, su imitación, su seguimiento, es el objetivo capital de Ignacio. Por eso, la pobreza y la humillación: "...Sefior..., que yo quiero y deseo y es mi determinación deliberada de imitaros en pasar todas injurias y todo vituperio y toda pobreza..."18. Más Jesús no fue pobre por ser pobre, ni padeció humillaciones por una humildad obsesiva. Pobreza y humillación son consecuencia de 
la misión evangelizadora que le confirió su Padre: evangelizar a los pobres, cuidar al rebanoo, distribuir todo bien, dar la vida... Por consiguiente, en esto reside la esencia del seguimiento: en misionar teniendo ante los ojos la misión de Jesús, en seguirlo -como aquellos doce- solidarizándose con su afán por liberar la tierra de toda dolencia, de todo mal, y colmarla de todo bien.

Como Cristo, pues, y como sus discípulos, la Companía de Jesús es esencialmente aposiblica. Ignacio la inscribe entre los primeros institutos religiosos que no priorizan la búqueda de la perfección personal, sino el bien de los projimos. La Companía existe para ser enviada a donde se espera mayor gloria de Dios y ayuda de las ánimas. Un Cristo en acción de conquista es quien seduce a Inigo, y el "trabajar con $\mathrm{El}^{\text {"19 }}$ en esa conquista es su gran pasión. Impulso apostólico que desea imprimir en los jesuitas; impulso que lo abarca todo, con tal de instaurar el reino: corresponden a la Companfía "todos los oficios de caridad que sirven para la edificación de las almas", declaró el Papa Julio III en su bula confirmatoria de 1550 .

Se trata de ese apostolado plural en el que Ignacio mismo se prodiga aun siendo ya general y debiendo, por tanto, gobernar una orden en acelerado crecimiento y redactar las Constiuciones. Encuentra tiempo para amparar judios en la propia casa, para promover la institución de un relugio para su catecumenado y para luchar por el respeto a sus derechos (sus familiares no convertidos los despojaban de toda propiedad y herencia). Funda la casa de huérfanos de Santa María de Aquino, el monasterio de Santa Catalina - para protección y educación de doncellas - y la hermandad de Nuestra Seffora de Gracia, en el templo de Santa Marta, para prostitutas en vía de regeneración: "ni sus canas, ni el oficio que tenía de prepósito general, eran parte para que él mismo en persona dejase de llevarlas y de acompaftarlas, por medio de la ciudad de Roma, cuando se apartaban de la mala vida"zo.

Con apoyo económico de Francisco de Borja, duque de Gandia, instaura en 1551 el Colegio Romano para la formación de sacerdotes de todas las nacionalidades; y en el 1552, el Colegio Germánico para un cuidado particular de los futuros sacerdotes alemanes que, por el protestantismo, no podían estudiar en su propia tierra y, por el protestantismo, deblan prepararse muy cualificadamente. Conscientiza a los médicos para que, a una con la salud del cuerpo, procuren la salud de los espiritus; confiesa (algunas veces "desde la mañana hasta la tarde... sin tomar alguna refección corporal ${ }^{n 21}$, imparte los Ejercicios, viaja a Paliano con el afán de reconciliar al matrimonio desavenido de Ascanio Colonna y Juana de Aragón; incansable escritor de cartas, lo mismo consuela a quien ha perdido a un ser amado que recomienda se unan a los misioneros de Etiopla "hombres de ingenio para darles industrias de hacer puentes para pasar rios, y fabricar y cultivar las tierras y pescar, y otros oficiales, y algún médico o cirujano..."2n, y etc...., etc... 
Con tan activo líder, no es de extrañar que, en pocos affos, los jesuitas inauguren colegios en Valencia, Valladolid, Gandía, Barcelona, Bolonia, Salamanca, y en ocho provincias de la Companía instaladas en campos de abundante protestantismo: Flandes, Reno, Suecia, Austria, Polonia, Aquitania y dos en Francia. No es de extrafiar que Francisco Javier esté en la India oriental, que los padres Juan Núflez y Luis González de Cámara sean enviados a Tremecén, Africa, a rescatar cristianos cautivos; que unos vayan a Manicongo, Etiopía occidental, y ouros sean apresados en Angola; y que suene ta hora de los primeros márires en tierras muy lejanas: el P. Anlonio Criminal, asesinado en Manancor, India; el P. Pedro Correa y el H. Juan de Sosa, muertos en Brasil. Todo retrata a una orden esencialmente apostólica.

\section{Disponibles a la universalidad, libres para el reino}

Ignacio de Loyola engendra a los jesuitas en una matriz: en los Ejercicios Espirituales, y, muy particularmente, en la meditación del reino. "Conquistar el universo mundo" para el Padre ${ }^{23}$ es la empresa de Jesús, rey eternal, y es la empresa del jesuita. De aqui la universalidad de la Companía, que incuye el apostolado plural y la apertura al ancho mundo -que ya estamos consignando-, y de aquí la exigencia de disponibilidad, de agilidad, de flexibilidad: ¡de libertad!

Sabor de universalidad y disponibilidad tienen las directrices fundamentales de la orden: "...E iremos sin tardanza... a cualesquiera provincia a donde nos enviaren, sin repugnancia ni excusarnos, agora nos envien a los urcos, agora a cualquier otros infieles, aunque sea en las partes que llaman Indias, agora a los herejes y cismáticos o a cualquier católicos cristianos" ${ }^{\text {24 }}$.

Y bajo el criterio de la universalidad y de la disponibilidad - ide la libertad máxima para el reino! - se va configurando la identidad y la práctica de la Companfa. Nace libre de "coro" (el canto en común del oficio divino) y libre de habito ("porque, habiendo necesariamente de tratar con los herejes y con otra gente desalmada y perdida - pues para ganar a éstos principalmente la enví Dios - que desprecia y aborrece el hábito de la religión, le ha parecido que podrá tener mejor entrada... no teniendo ella ningún hábitos. Nace libre de penitencias obligatorias y de cualquier ministerio que la inmovilice: ni parroquias, ni gobiemo, atención o confesión ordinaria de religiosas, ni siquiera "obligación de Misas perpetuas en sus iglesias ni cargos semejantes que no se compadecen con la libertad que es necesaria para nuestro modo de proceder in Dominio"2s.

También por esto, Ignacio rechaza -como por instinto- la consagración de obispos jesuitas: no solo por el riesgo de la pobreza, sino por la fijación que el cargo conlleva: "...el espíritu de la Companía es, en toda simplicidad y bajeza, pasar adelante de ciudad en ciudad, y de una parte a otra, no atacarnos en un particular lugar"27; "...los nuestros son caballos ligeros, que han de estar siem- 
pre a punto para acudir a los rebates de los enemigos, para acometer y retirarse y andar siempre escaramuzando de una parte a otra; para esto es necesario que seamos libres y desocupados de cargos y oficios que nos obliguen a estar quedos $^{\text {nza }}$. Escaramuzar, acometer, retirarse... Ignacio estaba pintando su autorretrato. Rivadeneira nos asegura que, tratándose de alguna fundación, "viendo que ya podía andar por sus pies... se salía, dando su lugar a otro,... a comenzar otras obras semejantes" ${ }^{\text {nza }}$.

Por nacimiento, pues, el jesuita está llamado a ser "vecino y morador del mundo universo"30, a despegarse, a "discurrir"... Su disponibilidad ha de excluir el "pedir gracia alguna al Sumo Pontífice ni a otra persona de fuera de la Companía, para sí o para otro" ${ }^{\text {"31. }}$ Y deberá ser un especialista en auxiliar a las personas mís desamparadas: "...todo esto hace la Compania, no solamente en las provincias y pueblos católicos, pero aun mucho más entre herejes y bárbaros, por ser más desamparados y necesitados de doctrina... ${ }^{n 2}$. Ningún aspecto del hombre puede ser marginado: el jesuita debe "consolar y dar alivio en lo que puede a todas las personas necesitadas y miserables... ${ }^{n 3}$. En congruencia con todo lo cual, el sacerdocio de los jesuitas (al que Ignacio no consagra ningún tratado especial en las Constiuciones) viene a ser tan pluriforme como su vocación apostólica, tan pluriforme como las dernandas todas del hombre en orden a la consumación del reino.

\section{Contemplativos en la acción}

Ahora bien, un cuerpo tan dinámico como debe ser la Compania, ıqué lugar da a la oración? Es imposible que Loyola, forjado por Dios en una pedagogía de autético misticismo (ilustraciones privilegiadas, lágrimas incontenibles, conmociones, trances...), descuide esa dimensión orante sin la cual todo apostolado naquea o pierde la brújula.

Pero la escuela de oración del fundador de la Companfa va a ser eximia en una característica de toda su espiritualidad: la integración de contravios. Muchas veces, la oración y la acción son concebidas y experimentadas como polos más en pugna que en complementación. Pues bien: el maestro Igracio aporta una altemativa audaz. Más allá del ora et labora de San Benito, y del contemplato aliis tradere (compartir a los demás lo contemplado) de santo Domingo, él propone una síntesis: "ser contemplativos en la acción".

No es ceoria utópica, es su realidad orante. Su Dirrio Espiritual nos lo muestra inundado de comunicaciones celestiales en medio del ajetreo de la vida La cotidianeidad lo ha persuadido de que se puede encontrar la palabra intima de Dios en todas las cosas y en todas las cosas - con nuestra acción mismapodemos responderle tambiên intimamente.

En esta actiud orante, o mejor, en este "actuar orante" procura él capacitar en el cierre de los Ejercicios Espirituales: en la contemplación para alcanzar 
amor. El santo se estremece -y espera que nos estremezcamos - captando en todas las cosas una presencia de Dios cálidamente amorosa y permanentemente activa: ad modum laborantis ${ }^{34}$. Quien obtiene el don de "conocer internamente tanto bien recibido" $\rightarrow$ través de la contemplación-, es transportado, proyectado...., queda impelido a un "eterno reconocimiento" $y$, en consecuencia, a "amar en todo y servir a su divina majestad"35. Así, en la vida diaria, el otrora y siempre recio soldado, Ignacio, para no estacionarse a medio camino, tiene que apartar con el bastón a una sencilla flor: "no me hables tanto de Dios". Y conffa en que con una sensibilidad semejante, el jesuita sea sin cesar atra/do a una respuesta de amor eficaz: anor "más en las obras que en las palabras" lugar a dudas, esta respuesta activa estará henchida de presencia del Sentor y podrá reciclar al coloquio Dios-hombre que, de esta forma, se vuelve ilimitado, sin fin.

Bajo esta visión de la actividad misma como fuente de un dílogo ininterrumpido con Dios, Ignacio llega a afurmar que "las cosas temporales... no solamente pueden ser equivalentes a la unión y recolección de la asidua contemplación, pero aun más aceptas, como procedentes de más violenta y fuerte caridad ${ }^{\text {37 }}$. Pero no es ingenuo. Por una parte, sabe que la "contemplación en la acción" exige cabal pureza de intención: "buscar en todas cosas a Dios nuestro Seffor, apartando - cuanto es posible- de sí el amor de lodas las criaturas por ponerle en el Criador dellas, a El en todas amando y a todas en El... ${ }^{34}$. Por otra parte, presupone que el apóstol jesuita no abandonará lo especifico de otras experiencias orantes como la eucaristía, el oficio divino, la meditación, el examen, etc.

Sin embargo, to peculiar del jesuita deberá ser ese como vivir inmerso en Dios. Y, ya que los estudios y la entrega apostólica reclaman todo el hombre, es preciso que, desde la formación, se ejercite "en buscar la presencia de nuestro Sefior en todas las cosas como en el conversar con alguno, andar, ver, gustar, oir, entender y en todo lo que hiciéremos... ${ }^{n 9}$. Esto incluso dispondrá para "grandes visitaciones del Seflor, aunque sean en una breve oración" ${ }^{\text {nto }}$. Y, definílivamete, hara de los jesuitas verdaderos "contemplativos en la acción".

\section{Guiados por el Espíritu, a través del discernimiento}

En realidad, los hijos de la Companía de Jesús, tal como los visualizo el fundador, tendrán que ser hombres de oración continua, no sólo por su calidad de "contemplativos en la acción", sino por una imprescindible escucha del Espíritu. Y no podía ser de otra forma, ya que el único gula que Ignacio tuvo en su vida fue el Espiritu de Dios (hizo consultas sf, y tomaba muy en cuenta cuanto le indicaban sus confesores; más no existe una persona concreta a quien pudiéramos llamar "el director o guía espiritual" de San Igmacio).

En su encuentro decisivo con Dios -quien le cambió derrotero y vida- 
Inigo descubrió que Dios comunica su Espíritu moviêndonos intemamente. Pero también detec 6 que estas mociones se dan en conflicto con todo un dinamismo de negatividad que nos mueve en sentido contrario. Dios, entonces, adiestró a Inigo en el uso de un instrumento al que confiará el caminar de la Compafía: el "discernimiento de espírilus", la capacidad de distinguir unas mociones de otras, y, asf, poder seguir la inspiración genuina del Espíritu de Dios.

Tal es la confianza de Ignacio en el Espíritu, tal primacía le concede, que categóricamente afirma en el inicio de las Constituciones: "...más que ninguna exterior constitución, la interior ley de la caridad y amor que el Espíritu Santo escribe e imprime en los corazones ha de ayudar para ello (para conversar, regir y llevar adelante esta Companía de Jesús)" ${ }^{n 1}$. Lo cual cree al grado de no preocuparse por una promulgación inmediata de las Constituciones, aunque los jesuitas se estén ya dispersando por el universo mundo. Tanto que san Ignacio -muerto en 1566- no estará presente en la aprobación definitiva de las Constituciones, hecha por la primera congregación general en 1558.

Todo es muy significativo, puesto que Ignacio redací esa carta magna de la Companía precisamente en estricto y muy esmerado discemimiento. El Diario Espiritual testifica cómo ponderaba cada asunto en la oración, en la misa, durante el día..., entre experiencias místicas en que perdía el aliento, el habla "palpitando sensiblemente todas las venas de su cuerpo" ${ }^{2}$. Cuarenta dias de oración y misa dedicó exclusivamente a discemir si las casas profesas deberian abstenerse de rentas. No obstante, para nada imprimió un carácter dogmático al documento. La necesidad de un ulterior discernimiento quedaba vigente.

Más aún, las Constituciones estún salpicadas de acotaciones que demandan ese discemimiento: el asunto "queda en la discreción del que tiene el cargo", "a juicio del Superior", etc... En lo cual no hay que olvidar que para Ignacio "discreción" significa "discernimiento de espiritus", y "discreta caridad" (norma de oro a la que acude con frecuencia) significa "el amor discernido en el Esplritu", y no simplemente una caridad modema, sensata, equilibrada.

Tal estructuración de la vida religiosa (nada férrea, monolitica y estandarizante - como en ocasiones erróneamente se piensa-) busca hacer de los jesuitas "hombres en permanente discernimiento" a la escucha del Esplitu, como el padre Ignacio, quien de nuevo - a través del discemimiento- integra factores que, en la práctica, se pueden vivir con tensión: el Espiritu y la ley, la vida y la autoridad, la libertad y la fidelidad, la mayor "eficacia" apostólica y el mayor seguimiento de Jesús.

El discemimiento asegura la vivificación del Espíritu, y evita que la letra de la ley traiga muerte; el discemimiento desenmascara aparentes eficacias apostólicas y ubica la eficacia real en un real seguimiento. Pero se requiere -eso si- sinceridad con Dios y con los superiores, pues son tantas nuestras "afeccio- 
nes desordenadas" que el discernimiento puede ser engafioso. Razón por la cual, en la Compania, las relaciones entre súbdito y superior se tienen que realizar en la base de una plena transparencia "...no le teniendo cosa cerrada ni aun la conciencia propia" ${ }^{n+3}$. Efectivamente, "...como siempre deben estar preparados para discurrir por unas partes y por otras del mundo..., para que se acierte en ales misiones... importa... sumanente que el Superior tenga plena noticia de las inclinaciones y mociones... ${ }^{\text {nt4 }}$. Es el privilegio, que la Compania ha logrado conservar, de la "cuenta de conciencia".

Es, pues, cauto san Igracio para que no haya engafios en la búsqueda de la voluntad de Dios (ןes su especialidad en los Ejercicios!); mas no suple ni apaga al Espiritu. Por consiguiente, los jesuitas -en relación consigo mismo y con toda persona - numca deberán ser "hombres de la ley", sino "hombres del Espíritun; nunca esclavos de las reglas, siempre libres con la libertad de los hijos de Dios que, por encima de toda norma, salvan la vida...

\section{Enviados por el vicario de Cristo}

Martín Lutero nace solamente ocho anos antes de Inigo de Loyola (en 1483); y su histórico cuestionamiento a la Iglesia (la publicación de las 95 tesis contra las indulgencias, el 31 de octubre de 1517) se verifica cuatro anos antes de la conversión del soldado de Pamplona. Por tanto, el crecimiento en la fe de lfitigo se habrá de dar en simultaneidad con la ebullición reformista del protestantismo que sacude a toda Europa Ambos, Lutero y Loyola, coinciden en sus aspiraciones de reforma; pero, mientras el religioso alemán —en el devenir de los acontecimientos - termina realizando su empresa desde fuera de la Iglesia, el santo espanol desarrolla su labor desde dentro de ella, con un carisma muy enfácico de fidelidad.

Es notable: ni las cárceles de Alcalá, ni las cadenas de Salamanca impuestas por "inquisidores eclesiásticos", ni los procesos, ni las prohibiciones de hacer apostolado -aun cuando no le probaran error alguno en su doctrina-, nada suscito rechazo o rebeldia de parte de Iñigo hacia la Iglesia. No cabe duda que el don de la vida nueva, recibido después del descalabro de Pamplona, conllevaba una adhesión inquebrantable a la "esposa de Jesucristo". Esta lealtad está en la base de cuanta ayuda espiritual ofrece desde que parte. de Loyola, hecho "otro hombre"; y no se deteriora jamás. Es como innata. En consecuencia, cuando el grupo de Paris quiere solemnizar con voto el proyecto de peregrinar a Tierra Santa, a Ignacio le parece evidente que -en caso de fallar el viaje a Palestina - deberian "presentarse al Vicario de Cristo, para que los emplease en lo que juzgase ser de más gloria de Dios y utilidad de las almas"4s.

Es lo que hicieron entre el 18 y el 23 de noviembre de 1538, al vencerse el plazo que hablan designado para desistir del viaje a Tierra Santa, inviable por los enfrentamientos marítimos de turcos y cristianos. Absolutamente lógico, 
pues, que —en continuidad con ese carismático "sentido de Iglesia" - la Companf́a nazca marcada con una especial vinculación con la cabeza visible de la Iglesia el Papa Los jesuitas se "asientan debajo del estandarte de la cruz, para ser soldados de Cristo y servir a sola su divina Majestad y a su esposa la santa Iglesia, son el Romano Pontffice, vicario de Cristo en la tierra" ${ }^{\text {46 }}$. Disponibilidad que queda sellada con un voto: "...demás de los tres votos comunes, nos obliguemos con este voto particular, que obedeceremos a todo lo que nuestro Santo Padre que hoy es, y a los que por tiempo fueran pontúlices romanos, nos mandaren..." ${ }^{n ?}$.

La "sim-patia" innata de Ifigo por la Iglesia indudablemente adquirió robustez y beligerancia en medio de la mayor crisis que ha sufrido el catolicismo en toda su historia: el cisma protestante. De aquí surge ef tinte combativo de la Companía en sus inicios: "fundada principalmente para emplearse toda en la defensión y dilatación de la santa fe católica ${ }^{\text {nse }}$. Pedro de Rivadeneira -pegado a Ignacio desde la adolescencia- escribe: "Ha sido invención de Dios el hacerse este voto en la Compañía en tiempos tan miserables y de tanta calamidad, en los cuales vemos que los herejes, con todas sus fuerzas y máquinas, procuran combatir la autoridad de la santa Silla Apostólica"49.

Con todo, esta solidaridad del jesuita con el Sumo Ponúfice (ordenada siempre al bien de la Iglesia universal) no tiene nada de "servilismon": es servicialidad corresponsable, es sumisión adulta. Obediencia pronta, sf, pero compaginada perfectamente con las demás facetas esenciales del molde jesultico: primado absoluto de Dios, seguimiento de Jesús pobre y humillado, prioridad del Espiritu sobre la ley, libertad para el reino. Todo lo cual permea la relación de Ignacio con la Santa Sede, Ignacio que propone iniciativas, que evita determinaciones funestas para la Compantia, que "representa" respetuosa pero eficazmente.

Pues, aunque Loyola pondera la obediencia hasta ser famoso por su ideal de una obediencia "ciega"so — como si fuésemos "un cuerpo muerto... o bastón de hombre viejo"s1; evidentemente deja espacio para una contraorden del Espíritu y contempla la posibilidad de la "representación": "Con esto no se quita que, si alguna cosa se os representase diferente de lo que al Superior, y, haciendo oración, os pareciese en el divino acatamiento convenir que se la representa sedes a él, que no lo podáis hacer"s2.

Con salvedades, por consiguiente, impuestas por la razón y la fe; pero es inequivoco que Ignacio desea poner a las ordenes del Papa un destacamento de hombres con profundo "sentido de Iglesia" (que "sienten con ella"), dispuestos para los más arduos frentes de batalla: "agora nos envien a los urros, agora a cualquier otros infieles, aunque sea en las partes que llaman Indias, agora a los herejes y cismáticos..." ${ }^{33}$. 
Definitivamente no había muerto el soldado de Loyola que sonaba con grandes proezas en servicio de su majestad. Solo habla cambiado de bandera, de causa, de rey. Y tan le sigue bullendo en las venas la sangre guerrera que ahora, soldado de Cristo y de la Iglesia (y hombre de su tiempo), elabora todo un plan para arrasar a los turcos con una "grande armada..., y aun, si fuese menester, trescientas velas, y las más o cuasi todas galeras..."; y lo envía al emperador Carlos V, en el supuesto de que la Compafía — de aceptarlo el Papa- dirfa ipresente!: "...podría ser que uno de los pobres de la Companía se pusiese en ellonsh.

Tales gestas ideaba el primer general de la Compania, Igmacio de Loyola En una época de inmensos retos (descubrimiento y colonización de nuevos mundos, rupura protestante), jufto con sus companteros habla concebido una Orden, la "mínima Companía de Jesús", para que fuera enviada por el vicario de Cristo, no a servicios mínimos, sino hacia las urgencias mórimas...

\section{Epílogo}

Estos fueron los principios ignacianos tanto en sentido temporal (la Compafía en tiempo de Ignacio) como en sentido inspiracional (las directrices fundantes). $Y$ ambos aspecios constituyen el sello ignaciano. A la luz de extos principios, los jesuitas deberan ser auténticos "hombres del más": siempre y en todo apóstoles, siempre y en todo aferrados a la mayor gloria de Dios y al "bien más universal" en servicio del projimo. Deberian ser "hombres con sentido cualificado de Iglesia", convocados para reformarla desde dentro, y asi -como Iglesia nueva - propagarla hasta los últimos rincones del universo mundo.

Deberan ser testigos y servidores de Dios -el Absoluto-, enamorados de Jesús con amor operante (amor que se vuelve seguimiento), y fieles al Espiritu. Deberían ser, finalmente, especialistas en la integración de los opuestos aparentes: "contemplativos en la acción" amonizando oración y acción; plenamente libres para el reino - "caballeria ligera"-, pero fieles, "prestos a la voz de la obediencia, como si de Cristo nuestro Seffor saliese, dejando por acabar cualquier letra o cosa... comenzada"s5; reglamentados hasta en la forma de locar la puertas, pero - por encima de cualquier autoridad o ley- seguidores del Espíritu, detectado mediante un continuo discernimiento.

Este carisma hecho vida, en los origenes ganó para la Compania el afecto y apoyo de innumeables personas; pero supuso penalidades sin fin, persecuciones y aun martirios. Ante esto, la Companía implantara con prudencia largas probaciones (a veces diez, doce y más aftos) corno condición para aceplar definitivamente a sus miembros, aunque ellos se comprometan para siempre a los dos afios de noviciado: "el cual (camino), porque hemos experimentado que liene muchas y grandes dificulades, nos ha parecido ordenar que ninguno sea admitido a la profesión en esta Compantía, si su vida y doctrina no fuera primero 
conocida con diligenúsimas probaciones de largo tiempo..." ${ }^{\text {57 }}$. Y, con sabiduria semejante, hace serias advertencias a quienes deseen incorporarse: "antes de echar sobre sus espaldas esta carga del Seftor, consideren mucho y por largo tiempo si se hallan con tanto caudal de bienes espirituales que puedan dar fin a la fábrica de esta torre ${ }^{\text {nge }}$.

Al cumplirse, pues, los 450 af́os del nacimiento de esta Companía en 1990 , y los 500 del nacimiento de Ignacio en 1991, espontáneamente se ocurre preguntar qué tan fiel sigue la Companía actual al sello ignaciano. No se trata de mimetismo. Esto sería lo más contrario a la mentalidad del fundador. Ignacio mismo fue trasladado de un deseo de imilar a pie juntillas a Jesús en Tierra Santa a una comprensión más profunda del seguimiento: seguir su inspiración y vida en Roma, en cualquier lugar del mundo... En esta 6ptica, a una Companía que, a través de la historia, ha sido presionada para que se vuelva más contemplativa en el sentido monástico, más atada a legalismos, menos "caballerfa ligera", menos pobre, y aun investida de dignidades...; a esta Companfa es fructuoso preguntarle qué tanto está siguiendo el carisma inicial, la inspiración de los primeros tiempos.

Ignacio mismo dejó planteado el reto para las generaciones futuras, para la generación actual: "Que donde... los primeros de la Compafía han pasado por esta necesidades y mayores penurias corporales, los otros que vinieron para ella, deben procurar por allegar cuanto pudieran adonde los primeros llegaron o más adelante en el Señor nuestro"s9.

\section{Notas}

1. Bula Exposcir débisum. Julio III.

2. Ejer. Esp. (23).

3. Ejer. Esp. (23).

4. Constituciones, p. X, n. 1, (812).

5. Ejer. Esp. (23).

6. Const. p. VII, c. 2, D. (622).

7. Ejer. Esp. (23).

8. $1 \mathrm{~J} \Omega, 1,1-3$.

9. Bula Exposcit débitum. Julio III.

10. Ejer. Esp. (95).

11. Op. cit. (94).

12. Bula Exposcit débirum. Julio II.

13. Const., Ex., c. 4, n. 44, (101).

14. Ibidem.

15. Bula Exposcit débitum. Julio III.

16. Carta n. 33, Obras Completas, BAC, 1963, p. 675.

17. Vida de Ignacio de Loyola. Pedro de Rivadeneira, libro III, c. IV. 
18. Ejer. Esp. (98).

19. Op. cis. (95).

20. Vida de Ignacio de Loyola. Rivadeneira, libro III, c. DX.

21. Cartas del P. Domenech. Dia 8 de marzo, (n. 136).

22. Carta n. 143, Obras Completas, BAC, 1963, p. 909.

23. Ejer. Esp. (95).

24. Bula Exposcit débitum. Julio III.

25. Vida de Ignacio de Loyola. Rivadeneira, libro III, c. XXI.

26. Const., p. VI, c. 3, n. 6 (589).

27. Carta n. 33, Obras Completas, BAC, 1963, p. 675.

28. Vida de Ignacio de Loyola. Rivadeneira, libro III, c. XIV.

29. Op. cit., libro II, c. DX.

30. Ibidem, c. XIV.

31. Conss. p. VL, c. I, n. 3 (552).

32. Vida de Ignacio de Loyola. Rivadeneira, libro III, c. XXI.

33. Ibidem.

34. Ejer. Esp. (236).

35. Ibidem (233).

36. Ibidem (230).

37. Carta al P. Menuel Godinho, n. 72, Obras Completas, BAC, 1963, p. 781.

38. Const., p. III, c. 1 (288).

39. Carta al P. Antonio Brandao, n. 66, Obras Completas, BAC, 1963, p. 761.

40. Ibidem.

41. Const., Proemio, n. 1, (134).

42. Vida de Ignacio de Loyola. Rivadeneira, libro IV, c. II.

43. Conss. P., IV, c. 10, n. 5, C y D, (424).

44. Op. cir., Examen, c. 4, n. 35 (92).

45. Autobiografla. San Ignacio de Loyola, c. VIII, n. 85.

46. Bule Expascis debitum Julio III.

47. Ibidem.

48. Ibidem.

49. Vida de Ignacio de Loyola. Rivadeneira, libro III, c. XXI.

50. Carla a los jesuitas de les casas de Romn, n. 59, Obres Completas, BAC, 1963, p. 754.

51. Const. , p. VI, n. 1, C, (547).

52. Carta a los Padres y Hermanos de Portugal, n. 86, n. 6. Obras Completas, BAC. 1963, p. 815.

53. Bule Expascir débitwn, Julio III.

54. Carre al P. Jenónimo Nadal, n. 77, Obras Completas, BAC, 1963, p. 786.

55. Const., p. VL, c. 1, n. 1, B. (547).

56. Thesaurus Spiritualis S. I., Sentander, 1950, Regles Comunes, r. 43 p. 227.

57. Buln Expascir débitun. Julio III.

58. Ibidem.

59. Cons., Exumen, c. 4, n. 26, (81). 